Article

\title{
Partisan Selective Exposure in Times of Political and Technological Upheaval: A Social Media Field Experiment
}

\author{
Cornelia Mothes $^{1, *}$ and Jakob Ohme ${ }^{2}$ \\ ${ }^{1}$ Department of Media and Communication, Technische Universität Dresden, 01069 Dresden, Germany; \\ E-Mail: cornelia.mothes@tu-dresden.de \\ ${ }^{2}$ Amsterdam School of Communication Research, University of Amsterdam, 1018 WV Amsterdam, The Netherlands; \\ E-Mail: j.ohme@uva.nl \\ * Corresponding author
}

Submitted: 7 April 2019 | Accepted: 13 June 2019 | Published: 30 July 2019

\begin{abstract}
Contemporary democracies are increasingly shaped by a surge of populism, posing serious threats to the idea of liberal democracy. Particularly in the run-up to elections, knowledge of such threats is essential for citizens to cast an informed vote. Against this background, the present study examined the likelihood of media users to engage with political news providing critical perspectives on populist movements in a 24-hour social media field experiment during the 2017 federal election campaign in Germany $(N=210)$. Based on two selective exposure measures, findings suggest that exposure to critical news is contingent upon the conceptualization of populist partisanship as a political orientation of either high commitment (i.e., voting intention) or high affinity (i.e., sympathy for a party). While high commitment triggered a rather classic confirmation bias, especially regarding click decisions, high affinity caused selection patterns to be more strongly guided by informational utility, particularly during newsfeed browsing, with counter-attitudinal information receiving more attention. When public sentiment cues were present, however, attitudinal patterns disappeared. These findings imply that partisan news use in times of political upheaval is best gauged by taking a closer look at the particular type of partisanship that guides selective exposure, as both types of partisanship caused contrary exposure patterns, and that today's news environments potentially override attitudinal influences by providing additional social monitoring cues.
\end{abstract}

\section{Keywords}

confirmation bias; incidental exposure; informational utility; online opinion; partisanship; populism; selective exposure; social endorsements; social media

\section{Issue}

This article is part of the issue "Selective Exposure in a Changing Political and Media Environment", edited by María Luisa Humanes (King Juan Carlos University, Spain).

(C) 2019 by the authors; licensee Cogitatio (Lisbon, Portugal). This article is licensed under a Creative Commons Attribution 4.0 International License (CC BY).

\section{Introduction}

In the run-up to elections, political news about the incumbent government and the political opposition help citizens cast an informed vote by providing clues on how to evaluate the government's past performance compared to competing party agendas. The media's public service function is becoming ever more important in recent years, with new right-wing populist movements starting to systematically challenge the consti- tutional foundation of liberal democracy and the performance of established democratic parties in Western democracies (Galston, 2018; Spruyt, Keppens, \& Van Droogenbroeck, 2016). Indeed, journalistic news coverage has been shown to monitor populist movements mainly from a critical-analytical perspective, seldom leaving populist statements by political actors unopposed and often taking a critical stance on populist parties to point out threats they potentially pose to democracy (Müller et al., 2017; Negrine, 2017). 
However, in times of disputed journalistic credibility in the wake of political polarization (Hanitzsch, Van Dalen, \& Steindl, 2018) and a diminishing public demand for journalistic news (Dahlgren, 2019), it remains an open question whether critical-analytical journalism is able to actually reach the public and, thus, contribute to enhanced public awareness of populist threats, especially when news consumption is now more commonly taking place in social, high-choice media environments.

Against this background, the present study investigates selective exposure to critical-analytical news on populism in a 24-hour social media field experiment during the 2017 federal election campaign in Germany, characterized by a surge of the right-wing populist party AfD. Based on an experimental design of high ecological validity, selective exposure will be examined-both as visibility time of posts in participants' newsfeeds and the number of posts participants clicked on-with regards to two main drivers of news exposure in times of political and technological upheaval, namely partisanship and public sentiment cues.

The findings of our study suggest that selective exposure research may benefit from differentiating more clearly between high party commitment and high party affinity as two separate constructs when examining the effects of partisanship on selective news exposure in the context of new political movements, as they appear to affect news exposure in opposite ways. Furthermore, social cues provided by today's news environments were found to be decisive in attenuating selection biases, increasing user openness across the political spectrum towards critical news regarding populism.

\section{Partisan Selective Exposure in Times of Political Upheaval}

Critical news coverage can essentially help citizens become aware of populist threats by clarifying the democratic implications of populist demands. However, extant research on confirmation bias in partisan selective exposure suggests that the actual awareness of such threats greatly depends on media users' political predispositions, as users tend to prefer information that aligns with their political preferences while avoiding-although to a smaller extent (Garrett, 2009)-information that challenges their viewpoints (Feldman, Wojcieszak, Stroud, \& Bimber, 2018; Knobloch-Westerwick, Mothes, Johnson, Westerwick, \& Donsbach, 2013).

The determining motivational drivers of confirmation biases are often explained by drawing on cognitive dissonance theory (Festinger, 1957). According to dissonance theory, individuals selectively approach attitude-bolstering content and avoid challenging information in order to reduce discomfort and maintain a consistent self-image (see also Aronson, 1999; KnoblochWesterwick, 2015). In the area of political communication, a mounting number of studies supports this notion, demonstrating the reinforcing effects of partisan selective exposure on political self-views as indicated by increased attitude strength or attitude accessibility (Knobloch-Westerwick, 2012; Matthes \& Schmuck, 2017), which in turn can stimulate further reinforcement of confirmation biases (Dahlgren, Shehata, \& Strömbäck, 2019; Stroud, 2010).

In social psychology, most consistent support for the notion of partisan selective exposure was found in instances of 'postdecisional' dissonance regarding past behaviours or beliefs held with strong commitment, thereby becoming less amenable to change (D'Alessio \& Allen, 2002; Mills, 1999). Hence, in pre-election contexts, partisan selective exposure is most likely to occur among voters who have already decided upon whom to cast their vote for. Although voting intentions can change over time, this scenario is unlikely for committed supporters of populist parties, as populism stresses partisanship to a special degree by cultivating strong ingroup favouritism, fostering positive political self-views through emphasizing an idealized homogeneity of the people, while simultaneously excluding non-compliant and non-eligible segments of the population as outgroups (Bos et al., in press; Jagers \& Walgrave, 2007).

From a social identity perspective, the sense of belonging to an ingroup is not unique to populism, but rather serves as a major reference point for media users in general to perform confirmation biases in the context of partisan news exposure (Stroud, Muddiman, \& Lee, 2014; Wojcieszak \& Garrett, 2018). The case of populism-more specifically right-wing populism-is special, however, in that the definition of the ingroup is far more exclusive and is accompanied by particularly strong affective appeals (Wirz, 2018). In contrast to its alleged representation of the people as a whole, rightwing populism actually draws a clear line between those who share its ideology and those who do not, reserving the right to belong-and thus access to the ingroupsolely for those who subscribe to the populist ideology (Berbuir, Lewandowsky, \& Siri, 2015). Accordingly, populist voters were shown to be particularly interested in political information that actively addresses the gaps between the 'innocent' ingroup and the 'culprit' outgroup (Hameleers, Bos, \& De Vreese, 2017). Not surprisingly, this anti-pluralism creates a particularly strong sense of a 'politicized self' (Bos et al., in press), which in turn leads to a generally greater perceived stigmatization by and actual skepticism of mainstream parties, their supporters, and the media (e.g., Eberl, 2019; Van Spanje \& Azrout, 2019). In light of the strong ingroup-outgroup polarization instigated by populist movements and against the background of the vast empirical evidence in support of general partisan confirmation biases, we, therefore, pose the following hypothesis:

$H 1$ : Prospective voters of a right-wing populist party will less be likely to expose themselves to critical news about their party than prospective voters of other parties. 
In the context of established democratic parties, partisanship was found to highly correlate with other types of political predispositions, such as issue positions, general political ideology, or sympathy for a given party (Jou \& Dalton, 2017; Knobloch-Westerwick \& Kleinman, 2012; Knobloch-Westerwick \& Meng, 2011; Stroud, 2010), each often yielding similar effects in terms of confirmation biases. However, this general consistency of political orientations-and their effects on selective exposure-may not equally apply to populism, as attitudes of populist sympathizers towards populism appear to be much more ambiguous and inconsistent than those of committed populist voters. In Germany, for example, only a minor part of the population would actually vote for the AfD (16\%) although a majority of citizens have been dissatisfied with the overall government performance (68\%) and its handling of immigration issues (51\%; Infratest Dimap, 2018), considered as two main drivers of voting in favour of right-wing populism (Reinemann, Aalberg, Esser, Strömbäck, \& De Vreese, 2017; Walgrave, Lefevere, \& Tresch, 2019). Especially the politically disenchanted segments of the electorate may thus sympathize with populist agendas in the run-up to an election but do not necessarily support populists in elections, not even for the purpose of protest voting (Giebler \& Regel, 2018). A major reason for this inconsistency likely lies in the political programs of populist parties themselves, as they are usually narrow in terms of their issue agendas, less clearly explicated, and far more reluctant to political compromise than the programs of established democratic parties (Fenger, 2018; Mudde, 2004; Reinemann et al., 2017). Voting for populist parties thus contains many unknown risks for sympathizers, as the outcomes of a populist party's election victory are less predictable.

In light of this uncertainty, citizens with an affinity for populist parties should not only considerably differ from sympathizers of mainstream parties in terms of their eventual commitment to the party; they should also differ from committed populist voters in terms of how they approach attitude-challenging information, such as critical news on populism. While classic confirmation bias frameworks suggest that sympathizers of established democratic parties show confirmation biases merely to a smaller extent due to lower levels of partisanship (e.g., Stroud, 2010), we expect populist sympathizers to not only show reduced levels of confirmation biases but to exhibit even inverse exposure patterns, caused by the high political uncertainty regarding populism's handling of a potential election victory. Hence, news exposure of populist sympathizers should not be primarily driven by aspirations to protect preexisting attitudes but more likely by a need for orientation (Arendt \& Fawzi, 2018), that is, by the informational utility of messages that critically examine populist movements before an election.

According to informational utility frameworks (Atkin, 1973; Knobloch-Westerwick, 2008), high uncertainty in how to adapt to the (political) environment leads media users to primarily engage with information that provides assistance in future decision making, regardless of whether it confirms or challenges previous attitudes. Accordingly, a study by Knobloch-Westerwick and Kleinman (2012) found that informational utility indeed overrides confirmation biases among voters who perceive high uncertainty before an election (see also Pearson \& Knobloch-Westerwick, 2019). While these studies, however, expected and found similar patterns across all supporters of a specific established democratic party-irrespective of their level of commitment to this party-the present study expects informational utility only to override confirmation biases among populist sympathizers due to their higher need for orientation in face of the risky and uncertain political enterprise populist parties stand for. In contrast to what was expected for prospective voters, we, therefore, pose the following hypothesis on partisanship with regards to less committed yet highly sympathetic party supporters:

$\mathrm{H} 2$ : Higher affinity for a right-wing populist party will lead to increased exposure to critical news about this party.

\section{Partisan Selective Exposure in Times of Technological Upheaval}

The effects of partisanship have been studied in various user contexts, with an increasing focus on online settings, related to vivid academic debates about the extent to which political preferences exert control over selective exposure in digital environments. While some scholars point to an increasing influence of political predispositions in times of 'echo chambers' and 'filter bubbles' (Bakshy, Messing, \& Adamic, 2015; Pearson \& KnoblochWesterwick, 2019), a majority of empirical studies found only limited support for a prevalence of partisan selective exposure online (Beam, Hutchens, \& Hmielowski, 2018; Nelson \& Webster, 2017). The latter findings are commonly explained by a greater likelihood of incidental exposure to attitude-challenging information due to increased content variety and weak ties to users with diverse opinions (Brundidge, 2010; Weeks, Lane, Kim, Lee, \& Kwak, 2017).

These potential constraints for partisan biases to occur online have been mainly discussed in reference to social media as increasingly prevalent news sources. On social media, users are thought to more likely to engage with cross-cutting news, as content is accompanied by social endorsements that provide important cues for media users to monitor their social environment-an observant behaviour of 'analytic labour' that has become habituated among online users to reduce uncertainty (Kaiser, Keller, \& Kleinen-von Königslöw, 2018; Karakayali \& Kilic, 2013). In contrast to user statistics (i.e., number of shares and views) or personal recommendations by friends, public sentiment cues such as 'likes' and additional emoticons should particularly suit media users' social monitoring aspirations, as they allow users to get an idea of what 
the broader online public sphere thinks about political issues (Porten-Cheé \& Eilders, 2019), thereby offering important heuristics for users to decide upon what information to access (Kaiser et al., 2018).

Although initial experimental studies indicate that public sentiment cues may indeed moderate the effects of political attitudes on selective news exposure (DvirGvirsman, 2019; Messing \& Westwood, 2014; Winter, Metzger, \& Flanagin, 2016), little is known as to whether this impact holds regarding populist movements, which particularly excel in using social media to spread their ideology (Ernst, Engesser, Büchel, Blassnig, \& Esser, 2017). Due to the remarkable ingroup favouritism encouraged by populism, heuristic cues on the general public perception of populism may be less relevant to committed populist voters than to populist sympathizers with a higher need for orientation. For the latter, however, the informational utility of heuristic social monitoring cues may either be diminished by the informational utility of the journalistic content or instead amplified in comparison to content-related informational utility due to it requiring less cognitive effort than exposure to counterattitudinal contents. Given the overall inconclusive expectations with regards to the effects of public sentiment cues, we examine the following research question:

RQ1: Do public sentiment cues alleviate the attitudinal effects as outlined in $\mathrm{H} 1$ and $\mathrm{H} 2$ ?

\section{Method}

\subsection{Overview}

To address the hypotheses and research questions, the present study examined partisan selective exposure to critical news posts on populism in a 24-hour social media field experiment during the 2017 federal election campaign in Germany. Participants browsed a mock newsfeed, with eight news posts explicitly including criticism of the German right-wing populist party AfD. While the content of the posts was held constant, public sentiment cues were randomly manipulated within subjects (no cues vs. 'likes' only vs. genuine cues with additional affective user reactions, such as 'angry' or 'love'). The distinction between 'likes' and genuine user reactions was made to ensure the comparability of findings with previous studies that mainly relied on 'likes' and for reasons of ecological validity, as the range of public sentiment cues on Facebook is constantly expanding.

\subsection{Participants}

Participants were recruited by an international online panel company that initially invited a national sample of 2,331 active social media users born in Germany to participate in the study in exchange for a monetary incentive. Of all panel members invited, 358 respondents participated in the study, corresponding to a response rate of
$15.4 \%$. Of those who completed the survey, 77 cases had to be excluded due to server problems, and a further 33 respondents were excluded on account of having participated via smartphone; in both cases, the validity of the recorded data could not be ensured. Finally, 38 respondents did not comply with the experimental instructions and were therefore also excluded from the analyses. The final sample thus consisted of 210 valid cases showing a satisfactory variation in sociodemographic variables, and a better representation of national German demographics than common experimental student samples (55\% male; mean age: $M=35$ years, $S D=9$; education: $52 \%$ secondary school, $28 \%$ high school, $17 \%$ graduate degree).

\subsection{Procedure}

In an online session of about 20 minutes, respondents indicated their political attitudes, among other variables, before they were redirected to the mock newsfeed and asked to browse its contents and to click on whatever posts they found interesting. To ensure that the experimental material was considered at least briefly, the time limit for newsfeed browsing was set to two minutes. The maximum time limit of ten minutes allowed participants to scroll through all material at a moderate pace without having time to read all posts in detail. On average, participants spent 4.50 minutes engaging with the newsfeed $(M=290 \mathrm{sec}, S D=162)$. Within the scheduled time for news browsing, participants were able to click on posts to get to the related full articles or videos and get back to the newsfeed for continued browsing. After browsing the news, participants completed a final questionnaire soliciting psychological and demographic variables.

\subsection{Newsfeed and Experimental Material}

The exposure task was administered by a software application that was specifically developed to simulate a Facebook-like newsfeed and to unobtrusively track selective exposure to each post. News posts and linked contents were collected from the 20 Facebook pages with the widest reach in Germany at that time, including political news (e.g., Spiegel Online, Bild) and entertainment news (e.g., Promiflash, sport1). A final sample of 100 posts, which were published by these Facebook pages on the day of the study, were displayed in a randomized order in the mock newsfeed to permit the study of partisan selective exposure under more realistic conditions.

The posts were shown to participants exactly as they appeared on the original Facebook sites with source, headline, subheading, picture, and teaser. To test for effects of public sentiment cues, however, the social endorsements associated with each post were randomly manipulated within subjects: participants saw the posts with either (a) no public sentiment cues, (b) 'likes' only, or (c) genuine affective reactions that each post had instigated in the online community (see Figure 1). 
§ FAZ.NET - Frankfurter Allgemeine Zeitung

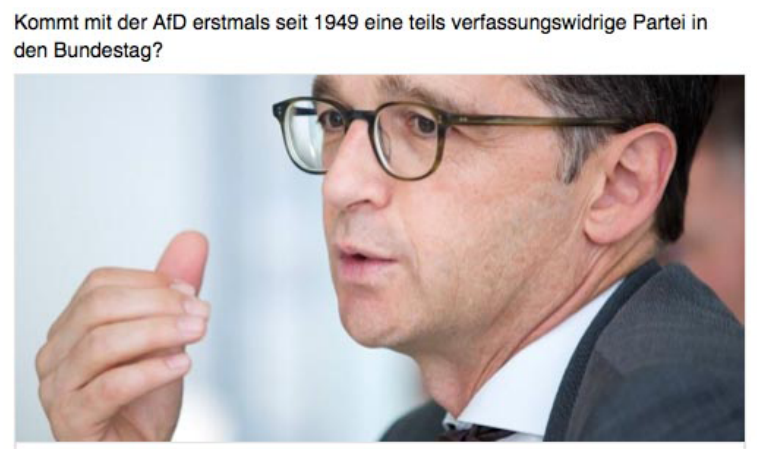

Bundestagswahl: Maas hält AfD-Wahlprogramm für verfassungswidrig

Der Justizminister zweifelt daran, dass das Programm der AfD mit dem Grundgesetz vereinbar ist. Von einer Blockade der Partei im Bundestag hallt Maas dennoch nichts.

\section{(1) 36}

Gefällt mir Kommentieren Teilen

Figure 1. Example screenshot of an AfD-critical post with genuine reactions.

Public sentiment cues were randomly assigned to the 100 posts and for each respondent individually based on nine categories with equal chances to be selected for display: (1) no public sentiment cues; (2) 1-6 'likes'; (3) 20-48 'likes'; (4) 127-406 'likes'; (5) 934-3,677 'likes'; (6) 1-6 genuine reactions; (7) 20-48 genuine reactions; (8) 127-406 genuine reactions; and (9) 934-3,677 genuine reactions (for a similar procedure see Dvir-Gvirsman, 2019; Winter et al., 2016). For reasons of ecological validity, each post thus had a 1:9 chance of being displayed without user reactions - on account of the fact that most posts receive at least some user reactions shortly after being published-and an equal chance of $4: 9$ of being displayed with either 'likes' or genuine user reactions. For the analyses, the categories were then merged into (a) no public sentiment cues, (b) 'likes' only, and (c) genuine public sentiment cues'. Applying this procedure, each individual AfD-critical post was displayed with no cues in $12 \%$ of cases, with 'likes' in $45 \%$ of cases, and with genuine user reactions in $43 \%$ of cases (for further details, see Table 1).

As the study utilized original, non-manipulated Facebook posts, two coders content analyzed the posts post hoc in terms of political relevance, reference to the AfD party, and mentioned criticism regarding the party. Among 42 overall political posts in the mock newsfeed (Krippendorff's Alpha $=.81$ ), nine posts mentioned the AfD (KAlpha $=1.00$ ), while eight included criticism regarding the AfD, mainly expressed through quoted actors and sources (KAlpha $=1.00)$. Regarding the pictures associated with the posts, four posts contained closeups of politicians who had made criticism towards the $A f D$, two posts used photos of AfD politicians, and two posts included rather abstract non-personalized pictures. One post referred to a video (source: Bild) that covered more than just the AfD, yet with criticism regarding the AfD serving as the lead story. The posts' sources reflect a combination of online outlets and subsidiaries of traditional newspapers (Bild, FAZ.NET), printed news magazines (Spiegel Online), and TV channels ( $n-t v)$, as well as genuine online sources (Tag24, wize.life, Epoch Times), with a balanced mix of sources across the political spectrum from left (e.g., Spiegel Online) to right (e.g., Epoch Times).

\subsection{Measures}

\subsubsection{Selective Exposure}

Two selective exposure measures were employed for each respondent: (a) visibility time of AfD-critical posts in the newsfeed (in $\mathrm{ms}$ ), captured by a digital meter point attached to each post; and (b) number of clicks on AfDcritical posts to get to the linked contents $(0=$ no $A f D$ critical post was clicked, 8 = all AfD-critical posts were clicked). For the final analyses, the only posts included were those which had been visible on the participants' screens for at least $50 \mathrm{~ms}$, representing the approximate average of an individual's ability to process the meaning of a picture (Potter, Wyble, Hagmann, \& McCourt, 2014). Furthermore, posts were only included if they had been visible for less than 15 seconds $(15,000 \mathrm{~ms})$ in order to avoid drawing inferences on the basis of visibility times that likely originated from user inactivity. The average visibility time across all valid posts was 3.62 seconds $(S D=3.23)$. The eight AfD-critical posts were visible for 16.08 seconds ( $S D=13.99$ ) on participants' screens. Regarding participants' click behavior, on average, respondents clicked on $4 \%$ of the posts they saw $(M=.04$, $S D=.20)$. The average number of AfD-critical posts that participants clicked on was $0.31(S D=0.61)$.

\subsubsection{Voting Intention}

To measure partisanship in terms of voting intention, participants were asked to indicate which of the German parties standing for election they were going to vote for. As populism relies on strong ingroup-outgroup polarization, participants who indicated voting for the AfD were classified as the 'ingroup' (19\%), whereas participants who did not indicate voting for the AfD were categorized as the 'outgroup' (62\%). Respondents who were undecided were excluded from the analyses (18\%), as their support for the AfD, or its lack thereof, could not be ensured.

\subsubsection{Party Affinity}

To measure partisanship in terms of party affinity, participants were asked to indicate how much they sympathize with the AfD on a 5-point scale ( $1=$ like not at all; $5=$ like very much; $M=2.15, S D=1.51$ ). 
Table 1. Overview of AfD-critical posts and random assignment of public sentiment cues per post $(N=210)$.

\begin{tabular}{|c|c|c|c|c|c|c|c|c|}
\hline Source & Spiegel Online & n-tv & Bild & FAZ.NET & Tag24 & wize.life & Epoch Times & Epoch Times \\
\hline $\begin{array}{l}\text { Headline } \\
\text { (transl.) }\end{array}$ & $\begin{array}{l}\text { Justice minister: } \\
\text { Maas calls parts } \\
\text { of AfD program } \\
\text { unconstitutional }\end{array}$ & $\begin{array}{l}\text { Maas picks } \\
\text { AfD } \\
\text { program to } \\
\text { pieces }\end{array}$ & $\begin{array}{l}\text { Will AfD e-mail } \\
\text { affair cost Weidel } \\
\text { her job? +++ } \\
\text { Hurricane Irma: } \\
\text { That's what } \\
\text { Florida looks like. }\end{array}$ & $\begin{array}{c}\text { Federal } \\
\text { election: Maas } \\
\text { calls AfD } \\
\text { program } \\
\text { unconstitutional }\end{array}$ & $\begin{array}{l}\text { Investigations } \\
\text { against } \\
\text { Gauland after } \\
\text { statement } \\
\text { against } \\
\text { Özuguz }\end{array}$ & $\begin{array}{l}\text { CSU secretary } \\
\text { general Scheuer: } \\
\text { Weidel's facade } \\
\text { conceals } \\
\text { 'Reichsbürger' } \\
\text { ideology" }\end{array}$ & $\begin{array}{c}\text { Maas: AfD } \\
\text { program 'partly } \\
\text { unconstitutional' } \\
\text { 'authoritarian } \\
\text { system, not for }\end{array}$ & $\begin{array}{l}\text { Künast fears AfD } \\
\text { in Bundestag: AfD } \\
\text { strives for an } \\
\text { democracy' }\end{array}$ \\
\hline $\begin{array}{l}\text { Original Public } \\
\text { Sentiment Cues }\end{array}$ & $\theta=20$ & 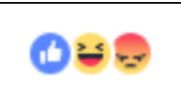 & $\theta=2$ & $\theta=8$ & $\theta 8$ & 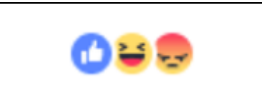 & $\ddot{\theta}=0$ & 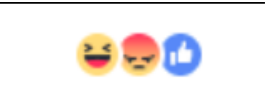 \\
\hline $\begin{array}{l}\text { No Public } \\
\text { Sentiment Cues }\end{array}$ & $13 \%$ & $10 \%$ & $10 \%$ & $14 \%$ & $12 \%$ & $9 \%$ & $11 \%$ & $15 \%$ \\
\hline 'Likes' Only & $42 \%$ & $47 \%$ & $43 \%$ & $47 \%$ & $51 \%$ & $43 \%$ & $42 \%$ & $47 \%$ \\
\hline $\begin{array}{l}\text { Genuine Public } \\
\text { Sentiment Cues }\end{array}$ & $45 \%$ & $43 \%$ & $47 \%$ & $39 \%$ & $37 \%$ & $48 \%$ & $47 \%$ & $39 \%$ \\
\hline
\end{tabular}




\subsubsection{Control Variables}

Additional measures were included to control for confounding influences of two basic individual predispositions known to affect selective exposure, political interest and dogmatism. Regarding political interest, respondents were asked to indicate their general interest in politics ( $1=$ not interested at all; $10=$ very interested; $M=7.35, S D=2.34)$. Dogmatism was measured by eleven items adopted from Shearman and Levine (2006), measured on 5-point scales ( $1=$ do not agree at all; $5=$ fully agree). The items were averaged to form an index of dogmatism ( $M=2.40, S D=0.54$, Cronbach's alpha $=.755)$.

\section{Results}

To test the effects of voting intention and party affinity on selective exposure to AfD-critical news posts with distinct public sentiment cues, a series of OLS regressions was conducted, one for each public sentiment cue type (no vs. 'likes' only vs. genuine). Based on two indicators of selective news exposure (visibility time, number of clicks), each model included voting intention and party affinity as predictors, while additionally controlling for age, gender, education, political interest, and dogmatism. Results are shown in Table 2.

Regarding news posts without public sentiment cues, the analyses revealed a confirmation bias for those who had already made up their minds about whom to cast their vote for in the upcoming election. In line with $H 1$, prospective AfD voters were less likely to spend time on AfD-critical posts in their newsfeed $(\beta=-.30, p=.054)$ and less likely to click on AfD-critical posts in order to engage with the linked contents $(\beta=-.38, p=.012)$. In total, prospective AfD voters spent $2966 \mathrm{~ms}$ less time on AfD-critical posts and clicked on 0.25 fewer AfD-critical posts than prospective voters of other parties.

Regarding party affinity, the analyses yielded reverse effects on selective exposure for those who tentatively identified with the party. In line with $\mathrm{H} 2$, higher affinity for the AfD led to longer visibility times of AfD-critical posts on the participants' screens $(\beta=.37, p=.02)$ and increased number of clicks on such posts $(\beta=.29$, $p=.069$ ). In total, visibility time of and number of clicks on AfD-critical posts increased by $952 \mathrm{~ms}$ and 0.05 clicks, respectively, with each scale point on the incremental AfD-affinity scale. ${ }^{1}$

When public sentiment cues were present, however, these attitudinal patterns disappeared, regardless of whether news posts were accompanied by 'likes' or additional affective user reactions (RQ1). Visibility time and number of clicks were no longer influenced by voting intention or party affinity ( $p s>10$ ), implying a conditional effect of partisanship on selective exposure to AfD-critical news posts contingent upon the presence of other users' reactions.

\section{Conclusions}

In recent years, whether or not citizens are aware of the challenges populism poses for liberal democracy has become a crucial question for communication scholars. This question primarily implies an openness for counterattitudinal information among supporters of populist parties. While cross-cutting exposure is generally conceived of as a decisive "criterion of citizen performance in democracy" (Chaffee, Saphir, Graf, Sandvig, \& Hahn, 2010 , p. 247), its practical implementation is a matter of constant debate. The present study aimed to further our understanding of the circumstances affecting receptiveness to attitude-challenging information by examining selective exposure to critical-analytical news posts on the German right-wing populist party AfD as a function of partisan commitment and social monitoring in a preelection context.

Our findings imply two distinct patterns of exposure to AfD-critical news posts, depending on participants' attitudinal commitment to the party. In line with $\mathrm{H} 1$, participants who have already decided to vote for the

Table 2. Impact of voting intention and political affinity on selective exposure to AfD-critical news posts by public sentiment cue type, beta weights ( $p$-values in parentheses).

\begin{tabular}{lcccccc}
\hline & \multicolumn{2}{c}{ No Public Sentiment Cues } & \multicolumn{2}{c}{ 'Likes' Only } & \multicolumn{2}{c}{ Genuine Public Sentiment Cues } \\
\cline { 2 - 7 } & $\begin{array}{c}\text { Visibility } \\
\text { Time }\end{array}$ & $\begin{array}{c}\text { Number of } \\
\text { Clicks }\end{array}$ & $\begin{array}{c}\text { Visibility } \\
\text { Time }\end{array}$ & $\begin{array}{c}\text { Number of } \\
\text { Clicks }\end{array}$ & $\begin{array}{c}\text { Visibility } \\
\text { Time }\end{array}$ & $\begin{array}{c}\text { Number of } \\
\text { Clicks }\end{array}$ \\
\hline AfD Voting Intention & $-.30(.054)$ & $-.38(.012)$ & $.13(.301)$ & $.04(.731)$ & $.01(.916)$ & $-.03(.839)$ \\
AfD Party Affinity & $.37(.02)$ & $.29(.069)$ & $-.12(.400)$ & $-.14(.288)$ & $-.14(.297)$ & $-.08(.578)$ \\
$R^{2}$ & .12 & .14 & .04 & .04 & .09 & .08 \\
$N$ & 103 & 103 & 155 & 155 & 155 & 155 \\
\hline
\end{tabular}

Notes: All analyses controlled for age, gender, education, political interest, and dogmatism, and showed acceptable variance inflation values of VIFs $<3$.

\footnotetext{
${ }_{1}$ Since two AfD-critical posts in the mock newsfeed were published by 'Epoch Times', which is known to be AfD-friendly, the analyses were re-run without these two posts in order to ensure the robustness of the findings. Results lean in the same direction, albeit with less power due to the reduced sample size.
} 
AfD were less likely to approach critical news about the party than the 'outgroup' of non-AfD voters, both in terms of how long they attended to posts in the experimental newsfeed and regarding their willingness to engage with linked contents. However, the effect was more pronounced regarding click decisions than attention allocation during browsing, indicating that committed partisans were more likely to incidentally encounter attitude-challenging information in social media environments without necessarily dealing with the information in more detail. This finding may help reconcile conflicting evidence on the persistence of confirmation biases in digital media environments by lending support for both the notion of incidental exposure (e.g., Nelson $\&$ Webster, 2017) and partisan selective exposure (e.g., Bakshy et al., 2015). Both exposure patterns appear to refer to different levels of news engagement, with exposure to counter-attitudinal contents being more pronounced on the level of peripheral elaboration in the course of newsfeed browsing. These results carry somewhat discouraging implications for citizens' awareness of populist threats, as confirmation biases appear to proliferate under circumstances of increased incidental exposure to attitude-challenging information. Incidental exposure may even have reinforced the active avoidance of contents linked to the posts, thereby potentially exacerbating political polarization (see also Weeks et al., 2017).

However, this notion only applies to committed voters and thus only to a fraction of a wider range of populist supporters. For the larger share of populist sympathizers, the analyses yielded opposite effects, in line with $\mathrm{H} 2$, by showing that participants with a higher affinity for the AfD were more likely to attend to and click on AfD-critical news posts. This finding supports the notion of a greater need for orientation among populist sympathizers, who were-following informational utility frameworks (e.g., Knobloch-Westerwick \& Kleinman, 2012)-expected to approach populism-critical news in order to reduce uncertainty regarding their political preferences. This notion is further supported by the finding that the effects of party affinity especially occurred during news browsing. Hence, the informational needs of populist sympathizers to learn about the democratic challenges posed by populism clearly dominate news exposure in the face of a multitude of alternative user options in high-choice media environments.

These findings extend previous research on established democratic parties by showing that new political movements are likely related to two distinct types of supporter which do not necessarily overlap: supporters with a high commitment to a populist party and supporters with a high affinity for a populist party's agenda. While prospective voters (high commitment) were more likely to avoid uncongenial information as commonly expected and found in extant research, party sympathizers (high affinity) were primarily interested in information that challenged their political preferences. While the first group may thus not be reached by critical news on pop- ulist threats to democracy and, hence, not be amenable to counterarguments, the latter and larger group of populist sympathizers appears significantly more open to deliberate discussions on populism. Given the shift to the right in many western democracies and an increasing polarization of the electorate along populist demarcation lines, our findings hence encourage a closer look at who we are talking about when speaking of populists and their potential resilience to the values of liberal democracy.

Our study additionally suggests that even confirmation biases shown by highly committed populist voters may be attenuated in social media environments. When populism-critical news posts were accompanied by public sentiment cues (RQ1), attitudinal impacts disappeared. In line with earlier research on the moderating role of social endorsements in partisan selective exposure (e.g., Winter et al., 2016), committed AfD voters did not differ significantly from non-AfD voters if social monitoring cues were present, suggesting that users tend to adapt to the social news environment instead of solely relying on individual predispositions (Porten-Cheé \& Eilders, 2019). Similar effects occurred with regards to populist sympathizers: exposure to AfD-critical posts was no longer decided upon AfD affinity under the presence of social monitoring cues, indicating that the informational utility of public sentiment cues exceeds messagerelated informational utility to a certain degree. Hence, heuristic cues appear to become increasingly decisive in what messages users engage with in social news environments. Even in case of high political commitment, such cues may provide important guidance for media users by satisfying an increasing need for 'analytic labour' (Karakayali \& Kilic, 2013), while simultaneously demanding little cognitive effort. This appears to apply both to classic 'likes' as aggregate forms of public approval (Winter et al., 2016) and to emoticons with a greater variety of expressed emotions. Although this study-due to its relatively small sample size-did not allow for a more detailed analysis of the specific number of public sentiment cues and its effects on selective exposure, these findings indicate that the mere presence of social cues may limit problematic selection biases and provide fertile ground for citizens-independent of their political background-to (re-)connect with political outgroups. In light of the increased need for social orientation in digital environments, future research should delve deeper into the question of exactly when and how this promising impact of social monitoring cues comes into play.

The findings of the present study need to be seen in light of several limitations. First, criticism regarding the AfD is likely related to a generally higher news value of negative information. Negativity bias could thus be a potential confound in our analyses of selective exposure (Meffert, Chung, Joiner, Waks, \& Garst, 2006) that could not be accounted for in the present study due to the high ecological validity of the design, using non-manipulated content actually published by main news sites. Hence, 
negativity bias should be considered in future research on populism by examining valence (negative, positive) and attitude-(in)consistency independently. The same limitation applies to the valence of public sentiment cues, as our field study did not to allow for systematic variation of genuine user reactions. As Table 1 showed, most of the original user reactions that were prompted by the eight AfD-critical posts contained a similar combination of emoticons (mostly 'angry' and 'amused'), along with 'likes'. This naturally existing user-generated material reflects not only a limited possibility for researchers to achieve satisfactory variation in social cues when relying on non-manipulated content, thereby complicating systematic comparisons; it also points to the difficulty of interpreting the messages that such combinations potentially send to the readers. In case of the combination of 'angry' and 'amused' cues, for instance, it remains unclear whether users thereby primarily perceive support or critique by other users with regards to what is mentioned in the post. Future research is needed to look deeper into the semantic meaning of combined affective user reactions in order to allow for a meaningful, systematic variation of public sentiment cues. On a related note, the present study examined attention to public sentiment cues only indirectly by inferring participants' awareness of such cues from observed user behaviours, following extant research in this area (Messing \& Westwood, 2014; Winter et al., 2016). Although this implies a certain risk of drawing false inferences if participants do not actually pay attention to such cues, studies utilizing eye-tracking during news browsing demonstrated that users do indeed take such cues into account when browsing and selecting information online (e.g., Dvir-Gvirsman, 2019). Future research should build on these findings to develop a valid and easy to implement measure of attention allocation towards social cues in order to allow for more rigorous manipulation checks and to thereby overcome the need for more complex field experiments to rely on indirect inferences when studying the effects of social cues. A related limitation of the study pertains to the indirect test of the effects of informational utility on selective exposure. Following approaches suggested by Knobloch-Westerwick and colleagues (Knobloch-Westerwick \& Kleinman, 2012; Pearson \& Knobloch-Westerwick, 2019), the present study implied greater utility of attitude-inconsistent posts among voters with a higher need for orientation, in this case, populist sympathizers. Future studies should take this approach further by directly measuring the perceived utility of attitude-consistent and counterattitudinal information as a function of political predisposition. Moreover, future research is needed to examine the specific motivational drivers of counter-attitudinal exposure exhibited by populist sympathizers, as they may influence information processing differently. On the one hand, the higher need for orientation among populist sympathizers may be related to accuracy motivations (Hart et al., 2009) to achieve an adequate under- standing of populism and could thereby promote political depolarization. This notion would be in line with findings by Beam et al. (2018) on the depolarizing effects of counter-attitudinal exposure on Facebook. On the other hand, the informational needs of populist sympathizers could also rely on defense motivations (Hart et al., 2009) to reinforce tentative attitudes by engaging in disconfirmation biases (Taber \& Lodge, 2006), which may eventually increase political polarization, as suggested by the findings of Weeks et al. (2017).

Besides these open questions-mostly originating from the study's aim to achieve high ecological validity, resulting in a more complex design compared to more traditional experimental studies-the ecological validity of this study has its limits, too. Specifically, exposure patterns of populist voters and sympathizers may be different if examined in even more natural exposure situations, because populists are commonly known to distrust mainstream media, as primarily-although not solelyexamined in the present study, to a special degree and to more strongly rely on alternative media (Haller \& Holt, 2018).

Despite these caveats, our study provides important insights on exposure to counter-attitudinal information in times of political and technological upheaval. By measuring partisanship in a more nuanced way and by studying exposure in realistic high-choice, social user settings, our findings suggest two main implications: first, that affinity to populism alone does not necessarily equate with intolerance towards populism-critical information, and second, that social cues provided by today's news environments may serve as decisive elements to contain selection biases to the benefit of a deliberate public discourse in turbulent political times.

\section{Acknowledgments}

We express our gratitude to Erich Stadler for his tremendous efforts in developing the software application used in this study. We furthermore thank Erich Stadler and Claudia Seifert for their help in crawling the news post material.

\section{Conflict of Interests}

The authors declare no conflict of interests.

\section{References}

Arendt, F., \& Fawzi, N. (2018). Googling for Trump: Investigating online information seeking during the 2016 US presidential election. Information, Communication, and Society. Advance online publication. https://doi.org/10.1080/1369118X.2018.1473459

Aronson, E. (1999). Dissonance, hypocrisy, and the selfconcept. In E. Harmon-Jones \& J. Mills (Eds.), Cognitive dissonance: Progress on a pivotal theory in social psychology (pp. 103-126). Washington, DC: Ameri- 
can Psychological Association.

Atkin, C. K. (1973). Instrumental utilities and information seeking. In P. Clark (Ed.), New models of communication research (pp. 205-242). Newbury Park, CA: Sage.

Bakshy, E., Messing, S., \& Adamic, L. (2015). Exposure to ideologically diverse news and opinion on Facebook. Science, 348(6239), 1130-1132. https://doi.org/ 10.1126/science.aaa1160

Beam, M. A., Hutchens, M. J., \& Hmielowski, J. D. (2018). Facebook news and (de)polarization: Reinforcing spirals in the 2016 US election. Information, Communication \& Society, 21(7), 940-958. https://doi.org/ 10.1080/1369118X.2018.1444783

Berbuir, N., Lewandowsky, M., \& Siri, J. (2015). The AfD and its sympathisers: Finally a right-wing populist movement in Germany? German Politics, 24(2), 154-178. https://doi.org/10.1080/09644008. 2014.982546

Bos, L., Schemer, C., Corbu, N., Hameleers, M., Andreadis, I., Schulz, A., . . Fawzi, N. (in press). The effects of populism as a social identity frame on persuasion and mobilization: Evidence from a 15-country experiment. European Journal of Political Research.

Brundidge, J. (2010). Encountering 'difference' in the contemporary public sphere: The contribution of the Internet to the heterogeneity of political discussion networks. Journal of Communication, 60(4), 680-700. https://doi.org/10.1111/j.1460-2466.2010.01509.x

Chaffee, S. H., Saphir, M. N., Graf, J., Sandvig, C., \& Hahn, K. S. (2010). Attention to counter-attitudinal messages in a state election campaign. Political Communication, 18(3), 247-272. https://doi.org/10.1080/ 10584600152400338

D’Alessio, D., \& Allen, M. (2002). Selective exposure and dissonance after decisions. Psychological Reports, 91(2), 527-532. https://doi.org/ 10.2466\%2Fpr0.2002.91.2.527

Dahlgren, P. M. (2019). Selective exposure to public service news over thirty years: The role of ideological leaning, party support, and political interest. The International Journal of Press/Politics. Advance online publication. https://doi.org/10.1177/ 1940161219836223

Dahlgren, P. M., Shehata, A., \& Strömbäck, J. (2019). Reinforcing spirals at work? Mutual influences between selective news exposure and ideological leaning. European Journal of Communication. Advance online publication. https://doi.org/10.1177/ 0267323119830056

Dvir-Gvirsman, S. (2019). I like what I see: Studying the influence of popularity cues on attention allocation and news selection. Information, Communication \& Society, 22(2), 286-305. https://doi.org/ 10.1080/1369118X.2017.1379550

Eberl, J.-M. (2019). Lying press: Three levels of perceived media bias and their relationship with political preferences. Communications, 44(1), 5-32. https://doi. org/10.1515/commun-2018-0002
Ernst, N., Engesser, S., Büchel, F., Blassnig, S., \& Esser, F. (2017). Extreme parties and populism: An analysis of Facebook and Twitter across six countries. Information, Communication \& Society, 20, 1347-1364. https://doi.org/10.1080/1369118X.2017.1329333

Feldman, L., Wojcieszak, M., Stroud, N. J., \& Bimber, B. (2018). Explaining media choice: The role of issuespecific engagement in predicting interest-based and partisan selectivity. Journal of Broadcasting \& Electronic Media, 62(1), 109-130. https://doi.org/ 10.1080/08838151.2017.1375502

Fenger, M. (2018). The social policy agendas of populist radical right parties in comparative perspective. Journal of International and Comparative Social Policy, 34(3), 188-209. https://doi.org/10.1080/21699763. 2018.1483255

Festinger, L. (1957). A theory of cognitive dissonance. Palo Alto, CA: Stanford University Press.

Galston, W. A. (2018). The populist challenge to liberal democracy. Journal of Democracy, 29(2), 5-19. https://doi.org/10.1353/jod.2018.0020

Garrett, R. K. (2009). Politically motivated reinforcement seeking: Reframing the selective exposure debate. Journal of Communication, 59(4), 676-699. https:// doi.org/10.1111/j.1460-2466.2009.01452.x

Giebler, H., \& Regel, S. (2018). Who votes right-wing populist? Geographical and individual factors in seven German state elections. Bonn: Friedrich-EbertStiftung. Retrieved from http://library.fes.de/pdffiles/wiso/14560.pdf

Haller, A., \& Holt, K. (2018). Paradoxical populism: How PEGIDA relates to mainstream and alternative media. Information, Communication \& Society. Advance online publication. https://doi.org/10.1080/1369118X. 2018.1449882

Hameleers, M., Bos, L., \& De Vreese, C. H. (2017). The appeal of media populism: The media preferences of citizens with populist attitudes. Mass Communication and Society, 20(4), 481-504. https://doi.org/ 10.1080/15205436.2017.1291817

Hanitzsch, T., Van Dalen, A., \& Steindl, N. (2018). Caught in the nexus: A comparative and longitudinal analysis of public trust in the press. The International Journal of Press/Politics, 23(1), 3-23. https://doi.org/ 10.1177\%2F1940161217740695

Hart, W., Albarracín, D., Eagly, A. H., Brechan, I., Lindberg, M. J., \& Merrill, L. (2009). Feeling validated versus being correct: A meta-analysis of selective exposure to information. Psychological Bulletin, 135(4), 555-588. https://doi.org/10.1037/a0015701

Infratest Dimap. (2018). ARD-DeutschlandTREND September 2018. Infratest Dimap. Retrieved from https://www.infratest-dimap.de/umfragenanalysen/bundesweit/ard-deutschlandtrend/2018/ september

Jagers, J., \& Walgrave, S. (2007). Populism as political communication style: An empirical study of political parties' discourse in Belgium. European Journal of 
Political Research, 46(3), 319-345. https://doi.org/ 10.1111/j.1475-6765.2006.00690.x

Jou, W., \& Dalton, R. J. (2017). Left-right orientations and voting behavior. Oxford Research Encyclopedia of Politics, 2017, 1-22. https://doi.org/10.1093/acrefore/ 9780190228637.013.581

Kaiser, J., Keller, T. R., \& Kleinen-von Königslöw, K. (2018). Incidental news exposure on Facebook as a social experience: The influence of recommender and media cues on news selection. Communication Research. Advance online publication. https://doi.org/ 10.1177/0093650218803529

Karakayali, N., \& Kilic, A. (2013). More network conscious than ever? Challenges, strategies, and analytic labor of users in the Facebook environment. Journal of Computer-Mediated Communication, 18(2), 175-193. https://doi.org/10.1111/jcc4.12005

Knobloch-Westerwick, S. (2008). Informational utility. In W. Donsbach (Ed.), International encyclopedia of communication (pp. 2273-2276). Oxford: Basil Blackwell.

Knobloch-Westerwick, S. (2012). Selective exposure and reinforcement of attitudes and partisanship before a presidential election. Journal of Communication, 62(4), 628-642. https://doi.org/10.1111/j. 1460-2466.2012.01651.x

Knobloch-Westerwick, S. (2015). The selective exposure self- and affect-management (SESAM) model: Applications in the realms of race, politics, and health. Communication Research, 42(7), 959-985. https:// doi.org/10.1177/0093650214539173

Knobloch-Westerwick, S., \& Kleinman, S. B. (2012). Preelection selective exposure: Confirmation bias versus informational utility. Communication Research, 39(2), 170-193. https://doi.org/10.1177/ 0093650211400597

Knobloch-Westerwick, S., \& Meng, J. (2011). Reinforcement of the political self through selective exposure to political messages. Journal of Communication, 61(2), 349-368. https://doi.org/10.1111/j. 1460-2466.2011.01543.x

Knobloch-Westerwick, S., Mothes, C., Johnson, B. K., Westerwick, A., \& Donsbach, W. (2013). Political online information searching in Germany and the United States: Confirmation bias, source credibility, and attitude impacts. Journal of Communication, 65(3), 489-511. https://doi.org/10.1111/jcom. 12154

Matthes, J., \& Schmuck, D. (2017). The effects of antiimmigrant right-wing populist ads on implicit and explicit attitudes: A moderated mediation model. Communication Research, 44(4), 556-581. https:// doi.org/10.1177/0093650215577859

Meffert, M. F., Chung, S., Joiner, A. J., Waks, L., \& Garst, J. (2006). The effects of negativity and motivated information processing during a political campaign. JournalofCommunication, 56(1), 27-51. https://doi. org/10.1111/j.1460-2466.2006.00003.x
Messing, S., \& Westwood, S. J. (2014). Selective exposure in the age of social media: Endorsements trump partisan source affiliation when selecting news online. Communication Research, 41(8), 1042-1063. https:// doi.org/10.1177/0093650212466406

Mills, J. (1999). Improving the 1957 version of dissonance theory. In E. Harmon-Jones \& J. Mills (Eds.), Cognitive dissonance: Progress on a pivotal theory in social psychology (pp. 25-42). Washington, DC: American Psychological Association.

Mudde, C. (2004). The populist zeitgeist. Government and Opposition, 39(4), 542-563. https://doi.org/ 10.1111/j.1477-7053.2004.00135.x

Müller, P., Schemer, C., Wettstein, M., Schulz, A., Wirz, D. S., Engesser, S., \& Wirth, W. (2017). The polarizing impact of news coverage on populist attitudes in the public: Evidence from a panel study in four European democracies. Journal of Communication, 67(6), 968-992. https://doi.org/10.1111/jcom.12337

Negrine, R. (2017). How did the British media represent European political parties during the European parliament elections, 2014: A Europeanized media agenda? The International Communication Gazette, 79(1), 64-82. https://doi.org/10.1177/ 1748048516656299

Nelson, J. L., \& Webster, J. G. (2017). The myth of partisan selective exposure: A portrait of the online political news audience. Social Media + Society, 3(3), 1-13. https://doi.org/10.1177/2056305117729314

Pearson, G. D. H., \& Knobloch-Westerwick, S. (2019). Is the confirmation bias bubble larger online? Preelection confirmation bias in selective exposure to online versus print political information. Mass Communication and Society. Advance online publication. https://doi.org/10.1080/15205436.2019.1599956

Porten-Cheé, P., \& Eilders, C. (2019). The effects of likes on public opinion perception and personal opinion. Communications. Advance online publication. https://doi.org/10.1515/commun-2019-2030

Potter, M. C., Wyble, B., Hagmann, C. E., \& McCourt, E. S. (2014). Detecting meaning in RSVP at $13 \mathrm{~ms}$ per picture. Attention, Perception \& Psychophysics, 76(2), 270-279. https://doi.org/10.3758/s13414013-0605-z

Reinemann, C., Aalberg, T., Esser, F., Strömbäck, J., \& De Vreese, C. H. (2017). Populist political communication: Toward a model of its causes, forms, and effects. In T. Aalberg, F. Esser, C. Reinemann, J. Strömbäck, \& C. H. De Vreese (Eds.), Populist political communication in Europe (pp. 12-25). London: Routledge.

Shearman, S. M., \& Levine, T. R. (2006). Dogmatism updated: A scale revision and validation. Communication Quarterly, 54(3), 275-291. https://doi.org/ 10.1080/01463370600877950

Spruyt, B., Keppens, G., \& Van Droogenbroeck, F. (2016). Who supports populism and what attracts people to it? Political Research Quarterly, 69(2), 335-346. https://doi.org/10.1177/1065912916639138 
Stroud, N. J. (2010). Polarization and partisan selective exposure. Journal of Communication, 60(3), 556-576. https://doi.org/10.1111/j.1460-2466.2010.01497.x

Stroud, N. J., Muddiman, A., \& Lee, J. K. (2014). Seeing media as group members: An evaluation of partisan bias perceptions. Journal of Communication, 64(5), 874-894. https://doi.org/10.1111/jcom.12110

Taber, C., \& Lodge, M. (2006). Motivated skepticism in the evaluation of political beliefs. American Journal of Political Science, 50(3), 755-769. https://doi.org/ 10.1111/j.1540-5907.2006.00214.x

Van Spanje, J., \& Azrout, R. (2019). Tainted love: How stigmatization of a political party in news media reduces its electoral support. International Journal of Public Opinion Research, 31(2), 283-308. https://doi. org/10.1093/ijpor/edy009

Walgrave, S., Lefevere, J., \& Tresch, A. D. (2019). Position, competence, and commitment: Three dimensions of issue voting. International Journal of Public Opinion Research. Advance online publication. https:// doi.org/10.1093/ijpor/edz006
Weeks, B. E., Lane, D. S., Kim, D. H., Lee, S. S., \& Kwak, N. (2017). Incidental exposure, selective exposure, and political information sharing: Integrating online exposure patterns and expression on social media. Journal of Computer-Mediated Communication, 22(6), 363-379. https://doi.org/10.1111/jcc4.12199

Winter, S., Metzger, M. J., \& Flanagin, A. J. (2016). Selective use of news cues: A multiple-motive perspective on information selection in social media environments. Journal of Communication, 66(4), 669-693. https://doi.org/10.1111/jcom.12241

Wirz, D. S. (2018). Persuasion through emotion? An experimental test of the emotion-eliciting nature of populist communication. International Journal of Communication, 12, 1114-1138.

Wojcieszak, M., \& Garrett, R. K. (2018). Social identity, selective exposure, and affective polarization: How priming national identity shapes attitudes toward immigrants via news selection. Human Communication Research, 44(3), 247-273. https://doi.org/10.1093/ $\mathrm{hcr} / \mathrm{hqx} 010$

\section{About the Authors}

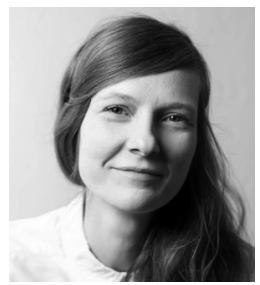

Cornelia Mothes is a Postdoctoral Researcher at the School of Media and Communication at Technische Universität Dresden. Her main research interests lie in the field of political communication, political journalism, and media psychology, with a focus on developing and testing communication strategies to increase political participation and political tolerance among the electorate in contemporary democratic societies. Cornelia's research is mainly based on experimental research with a strong emphasis on the practical applicability of experimental manipulations.

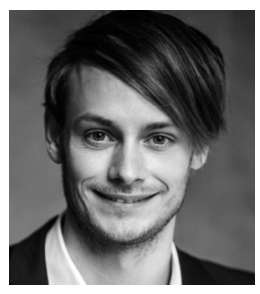

Jakob Ohme is a Postdoctoral Researcher in the Digital Communication Methods Lab at the Amsterdam School of Communication Research (ASCoR), University of Amsterdam. His research interests centre on political communication effects, the impact of digital media on political behaviour and attitudes, and the development of new methodological approaches in political communication research. As part of the Digital Communication Methods Lab at ASCoR, Jakob investigates effects of mobile media exposure by employing mobile methods, such as experience sampling studies, mobile eye-tracking, and the use of specific survey apps. 